\title{
Anesthetic management for a patient with severe mento-sternal contracture: difficult airway and scarce venous access -A case report-
}

\author{
Chong-Doo Park ${ }^{1}$, Hye-Kyoung Lee ${ }^{2}$, Ji-Yeon Yim², and Im-Hong Kang ${ }^{2}$ \\ Department of Anesthesiology and Pain Medicine, ${ }^{1}$ Dongnam Inst. of Radiological and Medical Sciences, Busan, ${ }^{2}$ Seoul National \\ University Hospital, Seoul, Korea
}

There are many problems in the anesthetic management of patients with scar contracture. In this case, a 41-yearold male with severe scar contracture on his face, neck, anterior chest, and both shoulders underwent surgery for resurfacing with flaps. We tried to awake fiberoptic orotracheal intubation with GlideScope ${ }^{\circledR}$ Video laryngoscope guide after surgical release of contracture under local anesthesia. We report a successful management of a patient with severe burn contracture achieved by combined effort of surgeons and anesthesiologists. (Korean J Anesthesiol 2013; 64: 61-64)

Key Words: Awake fiberoptic intubation, Burn contracture, Video laryngoscope.

For patients who develop scar contractures, resurfacing with flaps offers an optimal reconstructive outcome [1]. The anesthetic management of these patients presents many problems, such as difficult airway, scarce venous access, no places available for monitoring, drug dependency, multiple anesthetics, tendency to hypothermia, and inaccurate estimation of blood loss [2].

Because difficulty in managing the airway is one important cause of major anesthesia-related morbidity and mortality, preparations of many options for alternative to direct laryngoscopy must be made in advance. However, in patients with extreme contracture, the functional and anatomical distortion may lead to the failure of intubation. Hence, meticulous planning for anesthesia is essential to avoid catastrophic outcomes. We report a case of a patient with severe burn contracture involving neck, face, anterior chest, and both shoulders including upper arm that endotracheal intubation was achieved by combined effort of surgeons and anesthesiologists.

\section{Case Report}

A 41-year-old man was hospitalized with severe scar contracture due to flame burn injury to neck and chest three years ago. After undergoing several surgeries, his contracture got worse. He developed severe scar contractures involving neck, face, anterior chest, and both shoulders including upper arms

Received: February 6, 2012. Revised: April 9, 2012. Accepted: April 20, 2012.

Corresponding author: Chong-Doo Park, M.D., Department of Anesthesiology and Pain Medicine, Dongnam Inst. of Radiological and Medical Sciences, 40, Jwadonggil, Jangan-eup, Gijang-gun, Busan 619-953, Korea. Tel: 82-51-720-5114, Fax: 82-51-720-5353, E-mail: sunrud@naver.com (c) This is an open-access article distributed under the terms of the Creative Commons Attribution Non-Commercial License (http:// creativecommons.org/licenses/by-nc/3.0/), which permits unrestricted non-commercial use, distribution, and reproduction in any medium, provided the original work is properly cited. 
leading to severe deformity. His chin, chest, and both the upper arms were fused together by thick hard scars. Because of the contractures, he had to stay in a stooped posture with no neck flexion or extension. The cervicomental and the mentosternal angles were completely obliterated by thick stiff scars, and the anterior neck structures, including the larynx, the trachea, and the carotid arteries, were not identifiable or palpable (Fig. 1).

We consulted an otolaryngologist for airway evaluation, but endoscopic examination of the airway could not be performed because of the narrow external nares and the small oral opening. Preoperative X-rays and a computed tomography (CT) scan for assessing his airway passage and related structures revealed marked thickening of the soft tissues around the neck, without distortion or stenosis of the upper airway and the trachea.

In preoperative airway examination, the width from upper incisor to lower teeth was less than $1 \mathrm{~cm}$. Because of the restricted mouth opening, we could not perform modified Mallampati test (mMT). It was difficult to perform face mask ventilation because of nearly fixed neck movement and regressed mandible. For the same reason, conventional laryngoscopic intubation was thought to be impossible. Since the diameter of nares was about $0.5 \mathrm{~cm}$, it would be impossible to intubate the patient by nasal approach. So we considered several adjunctive methods, such as fiberoptic bronchoscopy, laryngeal-mask airway, lightwand or a GlideScope ${ }^{\circledR}$ Video laryngoscope, which might be used concomitantly. But there was no available noninvasive

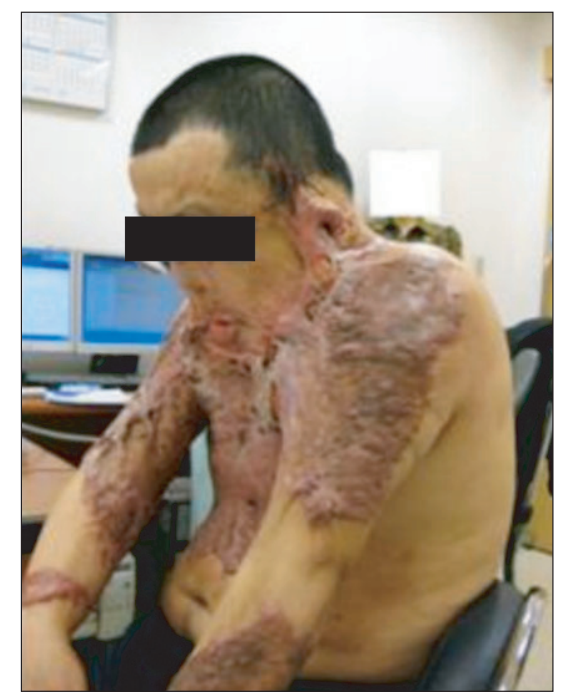

Fig. 1. Photographs of the Patient on Admission. There are severe contractures of the mandible, the neck and the lower part of the face, with narrow nares and a small oral opening (microstomia) that were due to the facial and perioral contractures. The neck is held in flexion, and the mandible is regressed and fixed near the sternum, impossible for the patient to extend the neck or distract the mandible. The structure of anterior neck is unidentifiable and impalpable. approach except orotracheal fiberoptic intubation while the patient is awake, or surgical tracheostomy.

The day before the surgery, a peripheral intravenous catheter was placed. Glycopyrrolate $0.2 \mathrm{mg}$ was delivered to the patient via intramuscular injection for reduction of oral secretions just before transferring to operating room. He was placed in the supine position on the operating table with standard monitor. The patient's vital signs were stable and he lay down comfortably on his back by stuffing the gap with pillow and folded sheets. The first attempt of awake fiberoptic intubation was performed after applying topical lidocaine spray to the oral cavity and pharynx. However, it was impossible to intubate with endotracheal tube through restricted mouth opening. Surgical tracheostomy wasn't possible either because thick scar made it impossible to identify the anatomy of the neck. So we decided to perform rapid surgery for release of the neck and mouth contractures under local anesthetic lidocaine (totally $400 \mathrm{mg}$ ) to improve his mouth opening by freeing the mandible from the scar. There were no systemic effects such as hypotension, bradycardia, arrhythmia, and seizure.

Initial scar releasing operation of the mouth and neck was done with intermittent administration of fentanyl (totally 200 $\mathrm{mcg}$ ). In spite of dissecting nearly the whole circumference of the neck, the mouth opening was only enough to allow passage of the blade of laryngoscope (Fig. 2).

Since it was impossible to identify glossopharyngeal nerve or superior laryngeal nerve even after releasing the contractures, we could not perform nerve block. After applying topical lidocaine spray to the oral cavity and pharynx, orotracheal

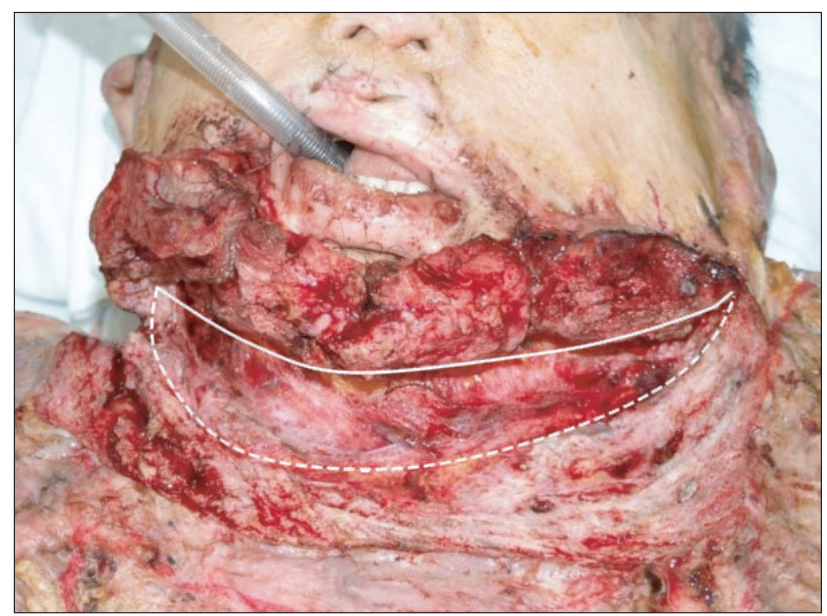

Fig. 2. Intubated state after release of the neck and mouth contractures. The solid line is drawn a transverse incision line under local anesthesia. And the part between a solid line and a dotted line is released area.; this requires dissecting nearly whole circumference of the neck, leaving a large, stellate wound involving the lower face, the neck, the upper chest. 


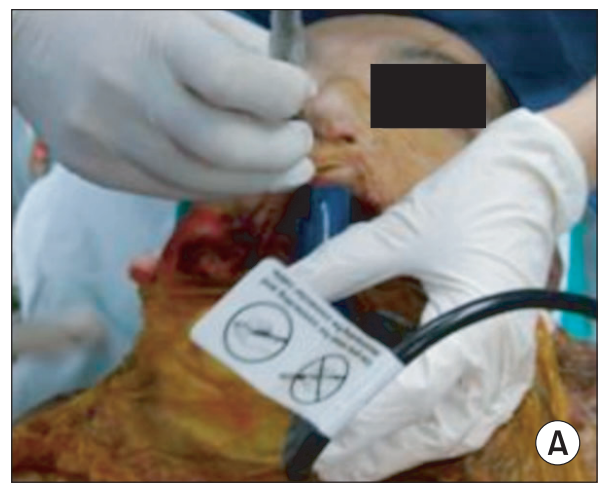

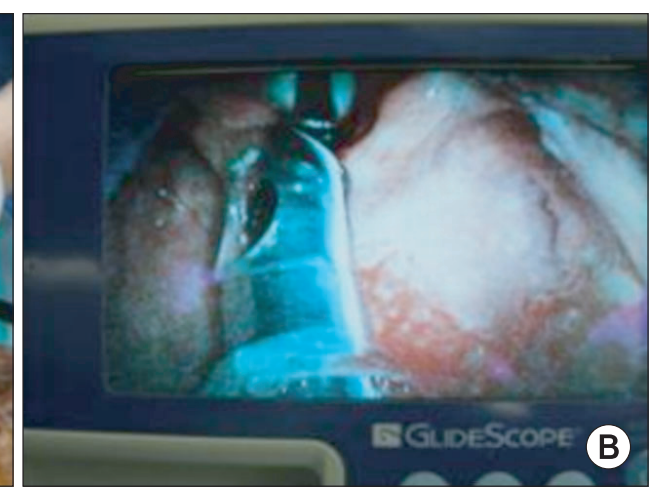

Fig. 3. (A) Awake intubation using fiberoptic bronchoscopy under GlideScope ${ }^{\circledR}$ Video laryngoscope guide. (B) The GlideScope ${ }^{\circledR}$ monitor display image of endotracheal tube passing through the vocal cord. intubation with a cuffed endotracheal tube (7.0 $\mathrm{mm}$ ID) was performed with the use of fiberoptic bronchoscopy under GlideScope ${ }^{\circledR}$ Video laryngoscope guidance (Fig. 3). There was no difficulty during the intubation. We confirmed the tube passing through the vocal cord and then it was fixed at mouth angle.

After the surgery, the patient remained with endotracheal tube and was transferred to surgical intensive care unit.

He received continuous infusion of midazolam and vecuronium for sedation and mechanical ventilation was maintained. Postoperative day 2, sedation was stopped and extubation was accomplished. After it, his spontaneous breathing was regular, chest movements were good. There was no hoarseness. Postoperative day 3 , the patient was moved to the general ward.

\section{Discussion}

The anesthetic management of patients with severe postburn neck contracture presents many difficult problems. Difficult airway is the most critical and its consequences can be catastrophic. An airway history and physical examination should be performed prior to the initiation of anesthetic care and airway management so that anesthesiologists can estimate the degree of airway difficulty and prepare several methods for airway management. The American Society of Anesthesiologists Task Force on Management of the Difficult Airway suggested several elements of the preoperative airway physical examination that may suggest the presence of a hard intubation during conventional oral laryngoscopy [3].

Many previous studies reported that modified Mallampati test (mMT) most commonly used single test for airway evaluation $[4,5]$. However, contracture of perioral area is accompanied in most mento-sternal contracture cases and, recently, it was reported that mMT is poor to be used alone in the clinical field because of low sensitivity and low positive predictive value [5]. Therefore, different criteria are needed. Currently, there are no recommended guidelines for burn scar patients, so airway management of these patients relies on clinical judgment of experienced anesthesiologist entirely.

There has been effort to classify burn scar patients according to the degree of contracture and evaluate airway based on previous studies. Onah [6] suggested a classification system with four major numeric categories, which is based on the extent of flexion or extension by the contracted neck and the anatomical position of the neck. Difficulty with intubation can be expected in type 2 and 3; especially in type 3, the distance between the chin and the thyroid prominence distance is shortened.

General available substitutes for difficult intubation are alternative laryngoscope blades, awake intubation, oral or nasal blind intubation, fiberoptic intubation, intubating stylet or tube changer, laryngeal mask airway (LMA) as an intubating conduit, lightwand, retrograde intubation, and invasive airway access [7]. ECMO is left as the last method.

In our case, because of the severe contractures and microstomia, direct visual examination of the oral cavity and pharynx was impossible. We excluded LMA because size \#4 for male adult was too large to pass through his mouth opening. Since it was not illuminated introducer due to presence of scar in the anterior aspect of neck, orotracheal intubation with lightwand was also excluded. We did not consider retrograde intubation or tracheostomy because the anterior neck structures including the larynx, the trachea, and the carotid arteries were not identifiable and not palpable. A different approach was needed.

Wong et al. [8] proposed several options for airway management with contractures involving the neck, face, and anterior chest. Those are: awake intubation with fiberoptic bronchoscopy, face mask ventilation followed by surgical scar release then tracheal intubation, laryngeal mask airway anesthesia and scar release then intubation if needed, intubating laryngeal mask airway, tracheostomy or cricothyroidotomy, and surgical scar release under ketamine local anesthesia then intubation. We chose awake intubation with fiberoptic bronchoscopy. In the first attempt, we could not put the endotracheal tube into patient's mouth because his mouth opening was less than 
$1 \mathrm{~cm}$ in width. Surgical scar release under local anesthesia for intubation was the only choice when awake fiberoptic intubation had failed.

Because induction of anesthesia and initial control of the airway are potentially hazardous [2,9], careful cooperative planning is necessary with surgery and anesthesia. Ideally, the surgeon should be in the room at the time of induction of anesthesia, prepared for emergency release of contractures, tracheotomy, or both. If intubation proves difficult or impossible, rapid partial release of the contractures can greatly assist intubation [9].

Use of ketamine is reported in previous clinical cases [10]. However fentanyl was injected intermittently for pain control because ketamine was not available in our hospital.

Releasing the contractures required dissecting nearly the whole circumference of the neck, leaving a large, stellate wound involving the lower face, the neck, the upper chest, and the upper arms. The total amount of lidocaine used in local anesthesia was about $400 \mathrm{mg}$ and fentanyl was $200 \mu \mathrm{g}$.

Despite surgical release, the mouth opening was not enough to conduct conventional intubation. We decided to perform awake intubation with fiberoptic bronchoscopy under GlideScope ${ }^{\circledR}$ Video laryngoscope guide.

In recent years, advances in optical technologies have enabled the development of several new indirect laryngoscopes, of which the GlideScope ${ }^{\circledR}$ Video laryngoscope is one [11]. This device visualizes the laryngeal inlet by indirect mechanisms, removing the need to align the oral, pharyngeal, and tracheal axes, thereby potentially making laryngeal visualization and subsequent tracheal intubation easier to perform. It is selfcontained, and very similar in appearance and technique to direct laryngoscopy, making this clinical approach very accessible [12]. But this device has limitations, with difficulties encountered in advancing the tracheal tube toward the view of the video monitor [13].

Disadvantages from this can be solved by using fiberoptic bronchoscopy as a guidewire. Fiberoptic bronchoscopy provides excellent visualization of glottis. Another major advantage of the fiberoptic technique under video guide is that the dynamics of endotracheal tube insertion can be continuously viewed on the screen until intubation is accomplished. If the endotracheal tube fails to enter the trachea directly, it may be manipulated under visual control [14].

Overall, fiberoptic bronchoscopy under video laryngoscope guide is a good suggestion in patients who cannot be ventilated or intubated easily.

In summary, difficulties with intubation are easily predicted who has severe scar contracture on his face, neck, anterior chest and both shoulders. Therefore, anesthesiologist must prepare for it.

We suggest two important points thought to be essential in airway management for scar contracture patients. First, careful cooperative planning by surgeons and anesthesiologists is essential; also, the surgeon should attend in the room at the time of induction of anesthesia, prepared for emergency release of contractures, tracheotomy, or both. Second, we propose an awake fiberoptic intubation under video laryngoscope guidance as an effective method in patients with anticipated difficult intubation.

\section{References}

1. Hormozi AK, Shafii MR. Mentosternal contracture treated with a massively expanded supraclavicular flap in a 25 -year-old man: a case report. Burns 2010; 36: e102-5.

2. de Campo T, Aldrete JA. The anesthetic management of the severely burned patient. Intensive Care Med 1981; 7: 55-62.

3. Rosen P, Sloane C, Ban KM, Lanigra M, Wolfe R. Difficult airway management. Intern Emerg Med 2006; 1: 139-47.

4. Savva D. Prediction of difficult tracheal intubation. Br J Anaesth 1994; 73: 149-53.

5. Wilson ME, Spiegelhalter D, Robertson JA, Lesser P. Predicting difficult intubation. Br J Anaesth 1988; 61: 211-6.

6. Onah II. A classification system for postburn mentosternal contractures. Arch Surg 2005; 140: 671-5.

7. Practice guidelines for management of the difficult airway: an updated report by the American Society of Anesthesiologists Task Force on Management of the Difficult Airway. Anesthesiology 2003; 98: 1269-77.

8. Wong TE, Lim LH, Tan WJ, Khoo TH. Securing the airway in a child with extensive post-burn contracture of the neck: a novel strategy. Burns 2010; 36: e78-81.

9. Sheridan RL, Ryan DP, Fuzaylov G, Nimkin K, Martyn JA. Case records of the Massachusetts General Hospital. Case 2-2008. Case 5-2008. An 18-month-old girl with an advanced neck contracture after a burn. N Engl J Med 2008; 358: 729-35.

10. Kreulen M, Mackie DP, Kreis RW, Groenevelt F. Surgical release for intubation purposes in postburn contractures of the neck. Burns 1996; 22: 310-2.

11. Choi GS, Lee EH, Lim CS, Yoon SH. A comparative study on the usefulness of the Glidescope or Macintosh laryngoscope when intubating normal airways. Korean J Anesthesiol 2011; 60: 339-43.

12. Cooper RM. Use of a new videolaryngoscope (GlideScope) in the management of a difficult airway. Can J Anaesth 2003; 50: 611-3.

13. Malik MA, O'Donoghue C, Carney J, Maharaj CH, Harte BH, Laffey JG. Comparison of the Glidescope, the Pentax AWS, and the Truview EVO2 with the Macintosh laryngoscope in experienced anaesthetists: a manikin study. Br J Anaesth 2009; 102: 128-34.

14. Kaplan MB, Ward DS, Berci G. A new video laryngoscope-an aid to intubation and teaching. J Clin Anesth 2002; 14: 620-6. 